\title{
Age, sex, ethnic origin and hospital admission for heart attack and stroke
}

\author{
D. G. BEEVERS \\ M.D., F.R.C.P. \\ J. K. CRUICKSHANK
M.B., M.R.C.P.
}

University Department of Medicine, Dudley Road Hospital, Birmingham B18 7QH

\begin{abstract}
Summary
The frequency of admission for heart attack and stroke in blacks, whites and Asians to Dudley Road Hospital, Birmingham, was studied. The study population (denominator) was 17739 consecutive admissions to this hospital for the years 1975 to 1979, in 35- to 64-year-old men and women. Admission for heart attack was half as common in blacks compared with whites and, in some age groups, there was a slightly increased rate in Asians. By contrast, in both sexes and in all age groups, stroke admission was commoner in blacks. These differences cannot be explained by differing levels of blood pressure or cigarette smoking in the 3 ethnic groups.
\end{abstract}

\section{Introduction}

Epidemiological studies and analyses of death certification in Britain have demonstrated important ethnic differences in the frequency of heart attack and stroke (Tunstall-Pedoe et al., 1975; Adelstein, 1978). These preliminary and often very small analyses have tended to show that heart attack is relatively uncommon in black people, and stroke more common, in comparison with Asians and whites. The authors conducted an analysis of 17739 admissions of patients to a large city centre hospital for both fatal and non-fatal heart attack and stroke with special reference to their place of birth, as well as to their age and sex.

\section{Methods}

All admissions and discharges to Dudley Road Hospital, Birmingham, are coded (using the HRM.1 proforma). Information is therefore available on age, sex, place of birth as well as discharge diagnosis. For the purpose of this analysis it was assumed that patients born in the West Indies are usually black, those born in India, Pakistan and Bangladesh are mostly Asian, and those born in Britain and Europe are mostly white. This reflects the fact that most immigration from the New Commonwealth took place in the 1950s and 1960s. Obviously, place of birth is not a reliable indicator of ethnic origin in children or young adults. Assuming that most of the immigrants were aged 20 and 30 years at the time of arrival, there should by now be significantly large minorities with both heart attack and stroke in city centre hospitals. At an early stage of this work, the authors did a manual check of patients admitted with heart attack in 1975 and were able to demonstrate that all West Indian born patients were black, those born in Asia were all Asian, and all patients born in Europe were white (Cruickshank et al., 1980).

\section{Results}

Between the years 1975 to 1979 inclusive, there were 17739 admissions for 35- to 64-year-old men and women under the care of the physicians of this hospital. In all except 1493 admissions (8.9\%), place of birth was coded on the HMR.1 record sheet. Of the remainder, $12976(79.9 \%)$ were European born; $1297(8.0 \%)$ were West Indian born; $1795(11.0 \%)$ were born in Asia; and 176 $(1 \cdot 1 \%)$ were born elsewhere. During this time, there were 1346 admissions for heart attack (ICD code 410-4109) of whom 1075 were European, 151 Asian and 42 West Indian. There were also 1138 admissions for stroke (ICD code 430-438) of whom 779 were European, 103 were Asian and 118 West Indian.

The admission rates have been calculated from the above data in each ethnic group for heart attack and stroke. Men and women were analysed separately for the age ranges 35-44, 45-54 and 55-64 years.

Heart attack was least common in the 35- to 44year-old age group in both men and women and occurred with increasing frequency with advancing age (Fig. 1). There was a smaller rise in the admission rate in men in the 45-54 and 55-64 years age groups. By contrast heart attack became progressively more frequent in women with advancing age, even though the admission rates were lower than in men. In both sexes and in all age groups, blacks had much lower admission rates for heart attacks, and there was some tendency for Asians to have higher rates than whites. 

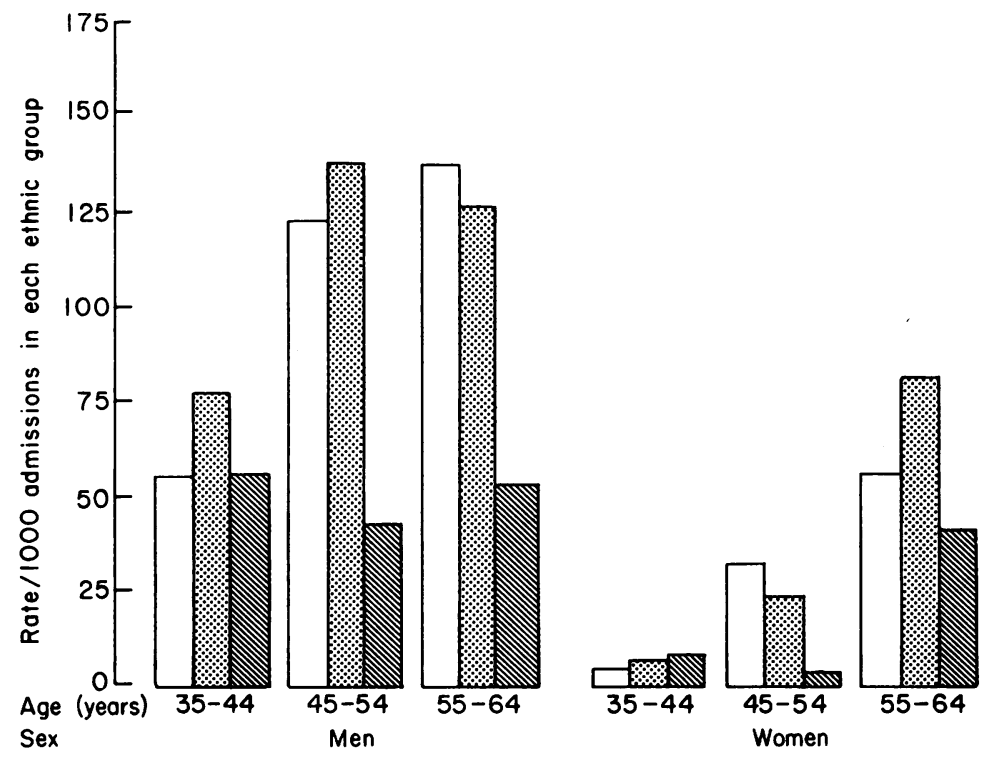

FIG. 1. The proportion of admissions for myocardial infarction (expressed as rate/1000 admissions) in men, women, European叉 $(\square)$, West Indians $(\mathbb{N})$ and Asians (웅) in relation to age.

The picture for admissions to hospital for stroke was very different (Fig. 2). There was a smaller difference between men and women, and no evidence of a 'fall off' in the rate of strokes in older men compared with older women. The admission rate for strokes was highest in blacks in both sexes की in all age groups.

\section{Discussion}

All the analyses presented here depend on the
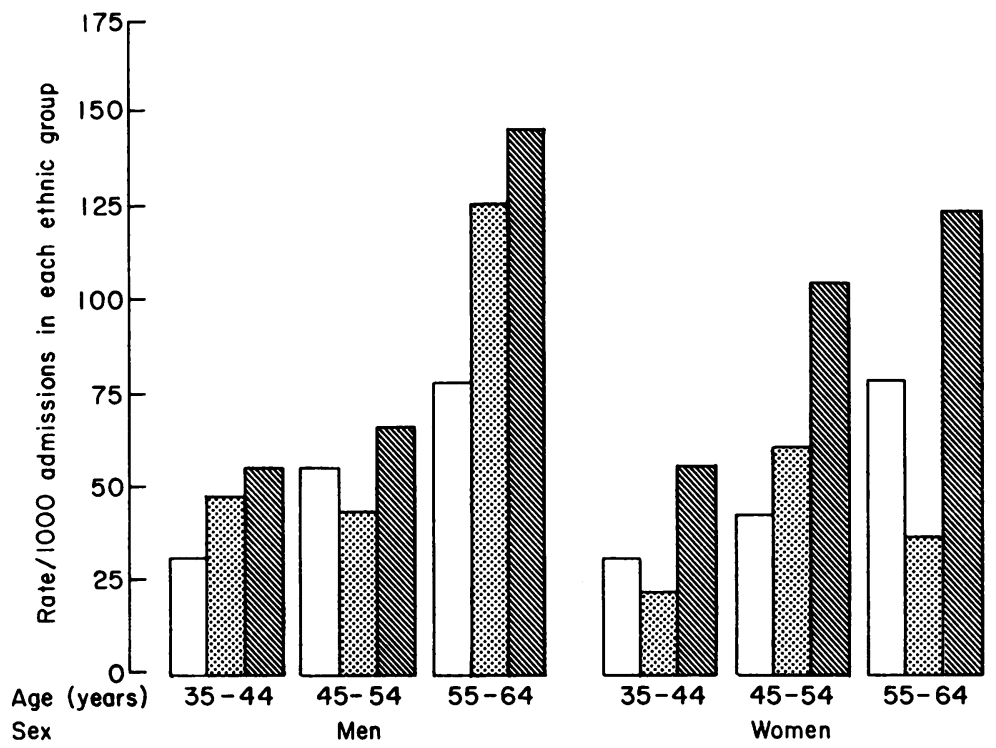

Fig. 2. The proportion of admissions for stroke (expressed as rate/1000 admissions) in men, women, Europeans ( $\square$ ), West Indians $(\mathbb{N})$ and Asians (圈) in relation to age. 
assumption that place of birth is a reliable indicator of ethnic origin. It is a pity that ethnic origin itself is not coded on the HMR.1 document or on death certificates. Over the next 20 years, research of this sort into ethnic differences in disease will become progressively more difficult.

These findings confirm the authors' clinical impressions and also the differences reported in the epidemiological survey in Tower Hamlets, London (Tunstall Pedoe et al., 1975), and the national Death Certification data (Adelstein, 1978). Furthermore, a similar relative rarity of myocardial infarction has been reported in blacks in the United States of America and Jamaica (U.S.A. Department of Health, Education and Welfare, 1976; Ashcroft and Desai, 1978). The most important factor in the British studies is that there are $\mathbf{2}$ immigrant groups and that they have widely different patterns of cardiovascular disease. A preliminary report from Trinidad has demonstrated similar trends for heart attack and stroke when comparing West Indian blacks with Asians living in the same area (Beckles and Millar, 1980).

Most epidemiological studies of cardiovascular risk factors have reported higher blood pressures in blacks when compared with whites (Freis, 1973). It is not known whether this is a genuine racial difference, or whether it merely reflects differences in social class. However, whatever the explanation, blacks could be expected to have more heart disease than whites. In fact they have less. These contrasts may be due to different rates of other coronary risk factors including serum lipids and cigarette smoking. It is probable that strokes are more directly related to the height of the blood pressure and that the ethnic differences can be explained accordingly.
In their epidemiological studies of factory workers (Cruickshank et al., 1981) the authors observed that cigarette smoking is nearly as common in blacks as in whites, and least common in Asians. The average age-related blood pressure in the 3 races showed only very minor differences. It seems unlikely that conventional cardiovascular risk factors can explain ethnic differences in heart attack and stroke.

\section{Acknowledgments}

We are grateful to Mr R. A. Haynes, West Midlands Regional HAA Officer, for providing us with data to analyse. A special tribute is due to Mrs E. Thomas and her staff at Dudley Road Hospital for their exceptionally reliable coding of HMR.1 documents.

\section{References}

ADELSTEIN, A.M. (1978) Current vital statistics: methods and interpretation. British Medical Journal, $2,983$.

AshCrofT, M.D. \& Desai, P. (1978) Blood pressure and mortality in a rural Jamaican community. Lancet, $\mathbf{i}, 1167$.

Beckles, G.L.A. \& Miller, G.J. (1980) Coronary risk factors in Trinidadian men and women aged 33-69 years. West Indian Medical Journal, 29, 312.

Cruickshank, J.K., Beevers, D.G., Bannan, L.T., JaCkson, S.H.D., Smith, M., Dianzumba, S. \& Denbow, C. (1981) Blood pressure and smoking habits in West Indians in Jamaica and in Birmingham in comparison with whites and Asians. Clinical Science, 60, 32pp.

Cruickshank, J.K., Beevers, D.G., Osbourne, V.L., Haynes, R.A., Corlett, J.C.R. \& Selby, S. (1980) Heart attack, stroke, diabetes and hypertension in West Indians, Asians and whites in Birmingham, England. British Medical Journal, 281, 1108.

FreIs, E.D. (1973) Age, race, sex and other indices of risk in hypertension. American Journal of Medicine, 55, 275.

Tunstall Pedoe, H., Clayton, D., Morris, J.N., Brigden, W. \& McDonalD, J. (1975) Coronary heart attacks in East London. Lancet, ii, 833.

U.S.A. Department of Health, Education and Welfare (1976) Vital and Health Statistics, 2, section 7. 